\title{
Relationship between downwelling surface shortwave radiative fluxes and sea surface temperature over the tropical Pacific: AMIP II models versus satellite estimates
}

\author{
C. Rodriguez-Puebla ${ }^{1}$, R. T. Pinker ${ }^{2}$, and S. Nigam $^{2}$ \\ ${ }^{1}$ Department of Atmospheric Physics, University of Salamanca, Spain \\ ${ }^{2}$ Department of Atmospheric and Oceanic Science, University of Maryland, MD, USA
}

Received: 11 June 2007 - Revised: 24 January 2008 - Accepted: 28 February 2008 - Published: 13 May 2008

\begin{abstract}
Incident shortwave radiation at the Earth's surface is the driving force of the climate system. Understanding the relationship between this forcing and the sea surface temperature, in particular, over the tropical Pacific Ocean is a topic of great interest because of possible climatic implications. The objective of this study is to investigate the relationship between downwelling shortwave radiative fluxes and sea surface temperature by using available data on radiative fluxes. We assess first the shortwave radiation from three General Circulation Models that participated in the second phase of the Atmospheric Model Intercomparison Project (AMIP II) against estimates of such fluxes from satellites. The shortwave radiation estimated from the satellite is based on observations from the International Satellite Cloud Climatology Project D1 data and the University of Maryland Shortwave Radiation Budget model (UMD/SRB). Model and satellite estimates of surface radiative fluxes are found to be in best agreement in the central equatorial Pacific, according to mean climatology and spatial correlations. We apply a Canonical Correlation Analysis to determine the interrelated areas where shortwave fluxes and sea surface temperature are most sensitive to climate forcing. Model simulations and satellite estimates of shortwave fluxes both capture well the interannual signal of El Niño-like variability. The tendency for an increase in shortwave radiation from the UMD/SRB model is not captured by the AMIP II models.
\end{abstract}

Keywords. Meteorology and atmospheric dynamics (Climatology; Ocean-atmosphere interactions) - Oceanography: general (Benthic boundary layers)

Correspondence to: C. Rodriguez-Puebla

(concha@usal.es)

\section{Introduction}

Climate projections depend on the ability to correctly represent the El Niño/Southern Oscillation (ENSO) phenomena in numerical climate models. Certain deficiencies in the simulation of the El Niño (Joseph and Nigam, 2006; van Oldenborgh et al., 2005), such as the intensity and location of its anomalies over the equatorial Pacific, can be attributed to processes that depend on the downwelling surface shortwave fluxes (hereafter $S W \downarrow_{\text {surf }}$ ). Satellites can provide largescale information on radiative fluxes and resulting products have been systematically evaluated against ground observations (Gupta et al., 1999; Li et al., 1995; Whitlock et al., 1995; Zhang et al., 2007). In this study it is assumed that the satellite-based estimates of $S W \downarrow_{\text {surf }}$ can be used for evaluation of products from numerical models. The model based estimates need to be evaluated against "observations" to improve parameterizations and to provide physical descriptions of observed events, such as ENSO. Here, the consistency of the $S W \downarrow_{\text {surf }}$ as produced by three models used in the Atmospheric Model Inter-comparison Project (AMIP II) experiments (http://www-pcmdi.llnl.gov/) is evaluated against $\mathrm{SW} \downarrow_{\text {surf }}$ derived from satellite observations. The models selected for comparison were: CCSM3 (USA) (Collins et al., 2006), UKMO-HadGEM1 (UK) (Gordon et al., 2000) and CNRM-CM3 (France) (Deque et al., 1994). The data used cover the period from July 1983 to June 2000, including notable El Niño and La Niña events. The period used is limited by the availability of SW $\downarrow_{\text {surf }}$ data from the AMIP II simulations, satellites and the most recent sea surface temperature (SST) data from the National Oceanic Atmospheric Administration (NOAA) (Reynolds et al., 2002). The comparison is performed over the tropical Pacific where a strong signal of interannual variability occurs.

Radiative fluxes from different models have been investigated in several recent studies. For example, Wielicki et al.

Published by Copernicus Publications on behalf of the European Geosciences Union. 
Table 1. AMIP II models used in this study.

\begin{tabular}{lccr}
\hline Model & Model Center & Resolution & Ref. \\
\hline CCSM3 (USA) & NCAR & Spectral T85 x L26 & Collins (2006) \\
UKMO-HadGEM1 (UK) & Hadley Center & N96 L38 & Gordon (2000) \\
CNRM-CM3 (France) & Meteo-France & Spectral T63 x L45 & Deque (1994) \\
\hline
\end{tabular}

(2002) have shown that model simulations fail to predict observed variation in the radiation emitted by the planet. Allan et al. (2004) evaluated the radiation budgets from the 40 Year Re-analysis (ERA-40) against satellite data; they found that the climatology of clear-sky shortwave radiation is well captured by ERA-40 while interannual changes are poorly simulated. Weare et al. (1995) observed similar patterns for cloudiness using models and satellite observations for the period 1979 to 1988 , though models gave smaller magnitudes of the variation. Stott et al. (2003) point out that climate models, such as the Hadley Center coupled atmosphereocean general circulation model (HadCM3), underestimate the observed climate response to solar forcing. Other studies have considered the interactions between radiative fluxes and ENSO phenomenon. For example, Chen et al. (2002) found an association between El Niño, and longwave and reflected shortwave radiation at the top of the atmosphere. Chou et al. (2004) stressed the importance of solar heating to explain the interannual variations of SST. Martin et al. (2004) also obtained El Niño signals in highly reflective clouds. Vecchi and Harrison (2003) point out that the interactions between anomalous El Niño conditions and the seasonal cycle of shortwave radiation may explain the processes that cause the end of the El Niño year. However, the links between $S W \downarrow_{\text {surf }}$ and SST using different types of data have not been investigated.

In the following section we briefly describe the data and methods used. Section 3 presents a comparison between $S W \downarrow_{\text {surf }}$ from General Circulation Models runs of the AMIP II outputs and from satellite estimates (hereafter UMD/SRB). We explore the connection between $\mathrm{SW} \downarrow_{\text {surf }}$ with El Niño and examine the trend of the simulated and satellite estimated $S W \downarrow_{\text {surf }}$ time series in Sect. 4. A summary of the major findings is provided in the Conclusion section.

\section{Data and methods}

The $S W \downarrow_{\text {surf }}$ from AMIP II models was evaluated against the $S W \downarrow$ surf produced with version 2.2 of the University of Maryland/Shortwave Radiation Budget (UMD/SRB) model. This model calculates fluxes in a vertically inhomogeneous scattering-absorbing atmosphere (Wiscombe, 1977; Pinker and Laszlo, 1992; Laszlo and Pinker, 1993; Pinker et al., 1995; Zhang et al., 2007). The satellite estimates have been evaluated against ground observations (Xia et al., 2006;
Zhang et al., 2007) and were included in a number of intercomparison efforts (Halthore et al., 2005).

The AMIP II models are available from the Program for Climate Model Diagnosis and Intercomparison (PCMDI) (http://www-pcmdi.llnl.gov/). We selected three models based on the closeness of their spatial resolution to the satellite data and on the best performance of the mean state compared to UMD/SRB data. Some characteristics, such as horizontal and vertical resolution and references that document the models are listed in Table 1. The monthly mean Sea Surface Temperature OI.v2 is produced on a one-degree grid using in situ and satellite data that are described and evaluated against observations in Reynolds et al. (2002) and Smith and Reynolds (2004). The analysis was performed for the period July 1983 to June 2000 over the region $140^{\circ} \mathrm{E}$ to $100^{\circ} \mathrm{W}$, $20^{\circ} \mathrm{S}$ to $20^{\circ} \mathrm{N}$. The monthly means from the AMIP II simulations and the SST data were re-gridded to the $2.5^{\circ}$ grid of the satellite SW $\downarrow_{\text {surf }}$. The reduced resolution of SST to match the resolution of $S W \downarrow$ surf did not affect this intercomparison study. In fact, the correlation between the SST time series averaged over the El Niño 3.4 region with and without re-gridding is 0.99 . The standard deviation of the re-gridded data decreased $15 \%$ with respect to the original data.

We use a sea level pressure gradient index $(\triangle \mathrm{SLP})$ computed from the difference in SLP anomalies with respect to the monthly means averaged over $\left(160^{\circ} \mathrm{W}\right.$ to $80^{\circ} \mathrm{W}, 5^{\circ} \mathrm{S}$ to $5^{\circ} \mathrm{N}$ ) and over $\left(80^{\circ} \mathrm{E}\right.$ to $160^{\circ} \mathrm{E}, 5^{\circ} \mathrm{S}$ to $5^{\circ} \mathrm{N}$ ) (Vecchi et al., 2006) to compare the changes in tropical Pacific circulation with the $\mathrm{SW} \downarrow_{\text {surf }}$ variations. The $\Delta \mathrm{SLP}$ index is derived from the reanalysis data of the National Centers for Environmental Prediction/National Center for Atmospheric Research (NCEP/NCAR) (Kalnay et al., 1996).

The Canonical Correlation Analysis (CCA) method was used to identify the regions of $S W \downarrow_{\text {surf }}$ that are dynamically connected with El Niño events. CCA is a statistical technique that identifies patterns in multivariate data sets and constructs transformed variables by projecting the original data onto these patterns. The new variables maximize the interrelationship between the two data sets. CCA is an extension of multiple regression and is useful in diagnosing aspects of the coupled variability of two fields (Wilks, 2006; von Storch and Zwiers, 1999).

The analysis was performed on anomalies or departures from the monthly mean at each grid point. The data are scaled by the square root of the cosine of the latitude to ensure that equal areas have equal influence. Bretherton 
(a) UMD/SRB

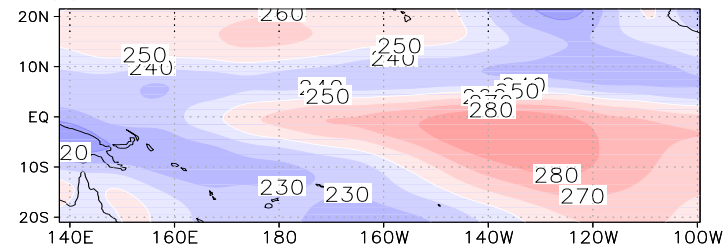

(c) UKMO-HadGEM1

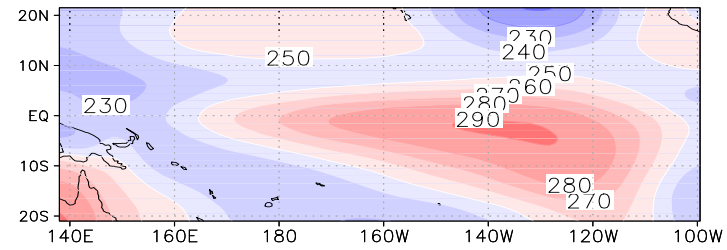

(b) CCSM3

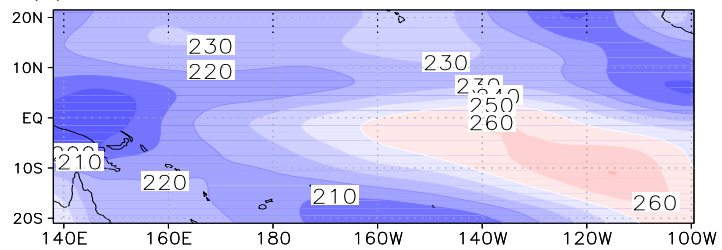

(d) CNRM-CM3

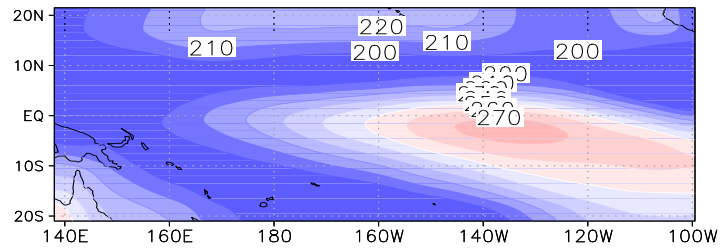

Fig. 1. Distribution of $S W \downarrow_{\text {surf }}$ over the tropical Pacific in $\mathrm{W} \mathrm{m}^{-2}$ from satellite estimates: (a) UMD/SRB and AMIP II models: (b) CCSM3; (c) UKMO-HadGEM1; (d) CNRM-CM3.

et al. (1992) have suggested pre-filtering of the two fields by applying Empirical Orthogonal Functions (EOF) (Jolliffe, 2002) before computing CCA. Therefore, the $S W \downarrow_{\text {surf }}$ and the SST data were prefiltered by replacing them with a truncated set of their principal components. Livezey and Smith (1999) provide some guidance to this approach, which has become a conventional procedure for data reduction. The interrelationships were measured in terms of the correlation coefficients between the canonical components associated with the leading modes. The errors of the correlation coefficients were derived by a re-sampling procedure with the bootstrap method (Wilks, 1997).

Trends of SW $\downarrow_{\text {surf }}$ from UMD/SRB and AMIP II models were obtained by a nonlinear regression method using a weighted least-squares fit of the anomalies to time (IMSL, 1997). The significance of the trend was measured by the non-parametric Kendall's Z test (Press et al., 1996), by substracting the number of discordant pairs from the number of concordant pairs. The significant trend at the $95 \%$ level corresponds to the $\mathrm{Z}$ test greater than $|2|$. Weatherhead et al. (1998) proposed a formula to obtain the number of years necessary to detect a trend because the precision is affected by the variability and autocorrelation of the data. The numbers of years used in our study to detect the trend is within the required interval. The Wang et al. (2007) test was used to check the homogeneity of the time series before obtaining the trend, the test detects undocumented discontinuities in climate data series or whether the values are statistically different from the most probable values.

\section{Assessment of AMIP II model performance}

Figures 1a to $d$ show the average $S W \downarrow_{\text {surf }}$ data from the AMIP II models and from the UMD/SRB estimates, show-

\section{(a) CCSM3 - UMD/SRB}

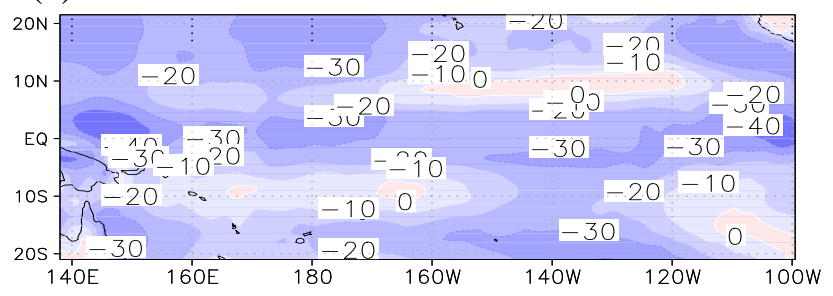

(b) UKMO-HadGEM1 - UMD/SRB

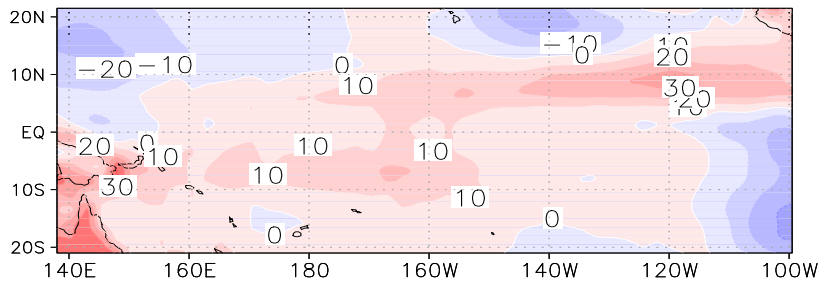

\section{(c) CNRM-CM3 - UMD/SRB}

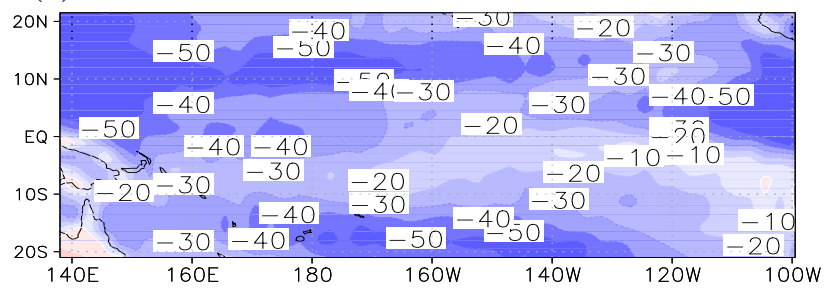

Fig. 2. Difference between $S W \downarrow_{\text {surf }}$ from AMIP II models and the UMD/SRB estimates in $\mathrm{W} \mathrm{m}^{-2}$ : (a) CCSM3; (b) UKMOHadGEM1; (c) CNRM-CM3.

ing similar patterns. Larger values are seen over the eastern Pacific $\left(300 \mathrm{~W} \mathrm{~m}^{-2}\right)$ while lower values are found over 
Table 2. Correlation coefficients, and their error interval, between shortwave $S W \downarrow_{\text {surf }}$ averaged over El Niño 4 region and sea surface temperature SST averaged over El Niño 3.4 region; and the $\triangle \mathrm{SLP}$ or the difference in sea level pressure over $\left(160^{\circ} \mathrm{W}\right.$ to $80^{\circ} \mathrm{W}, 5^{\circ} \mathrm{S}$ to $\left.5^{\circ} \mathrm{N}\right)$ and over $\left(80^{\circ} \mathrm{E}\right.$ to $160^{\circ} \mathrm{E}, 5^{\circ} \mathrm{S}$ to $\left.5^{\circ} \mathrm{N}\right)$. Regression coefficients, and their error interval, between SW $\downarrow_{\text {surf }}$ and SST in W m ${ }^{-2}$ per degree; and between $S W \downarrow_{\text {surf }}$ and $\Delta$ SLP in $\mathrm{W} \mathrm{m}^{-2}$ per hPa.

\begin{tabular}{lcccr}
\hline SW $\downarrow_{\text {surf }}$ & $\begin{array}{c}\text { Correlation } \\
\text { SST(3.4) }\end{array}$ & $\begin{array}{c}\text { Regression } \\
\text { SST(3.4) }\end{array}$ & $\begin{array}{c}\text { Correlation } \\
\Delta \text { SLP }\end{array}$ & $\begin{array}{r}\text { Regression } \\
\Delta \text { SLP }\end{array}$ \\
\hline UMD/SRB(4) & $-0.83 \pm 0.02$ & $-13.3 \pm 2.6$ & $0.89 \pm 0.01$ & $13.6 \pm 2$ \\
CCSM3(4) & $-0.79 \pm 0.03$ & $-11.8 \pm 2.5$ & $0.77 \pm 0.03$ & $10.6 \pm 1.6$ \\
UKMO-HadGEM1(4) & $-0.86 \pm 0.02$ & $-13.3 \pm 2.2$ & $0.82 \pm 0.02$ & $11.8 \pm 2.3$ \\
CNRM-CM3(4) & $-0.83 \pm 0.02$ & $-16.8 \pm 3.1$ & $0.76 \pm 0.03$ & $14.3 \pm 3.4$ \\
\hline
\end{tabular}

Table 3. Correlation coefficients, and their error interval, between shortwave $S W \downarrow_{\text {surf }}$ averaged over El Niño 4 region for AMIP II and $\mathrm{UMD} / \mathrm{SRB}$ models. Standard deviation of SW $\downarrow_{\text {surf }}$ (STD). Linear trend and significance of the trend (Kendall's Z test).

\begin{tabular}{lcccr}
\hline SW $\downarrow_{\text {surf }}$ & $\begin{array}{c}\text { Correlation } \\
\mathrm{UMD} / \mathrm{SRB}(4)\end{array}$ & $\begin{array}{c}\mathrm{STD} \\
\mathrm{W} \mathrm{m}^{-2}\end{array}$ & $\begin{array}{c}\text { Linear trend } \\
\mathrm{W} \mathrm{m}^{-2} \text { per year }\end{array}$ & Kendall's Z test \\
\hline UMD/SRB(4) & 1.0 & 16.2 & 0.52 & 2.25 \\
CCSM3(4) & $0.77 \pm 0.03$ & 15.1 & -0.09 & -0.31 \\
UKMO-HadGEM1(4) & $0.82 \pm 0.02$ & 15.6 & -0.009 & -0.13 \\
CNRM-CM3(4) & $0.74 \pm 0.03$ & 20.4 & 0.024 & 0.06 \\
\hline
\end{tabular}

the western Pacific $\left(200 \mathrm{~W} \mathrm{~m}^{-2}\right)$. Figures $2 \mathrm{a}$ to $\mathrm{c}$ show the $\mathrm{SW} \downarrow_{\text {surf }}$ difference between the AMIP II and UMD/SRB. In general, the CCSM3 and CNRM-CM3 models underestimate $\mathrm{SW} \downarrow_{\text {surf }}$ while the UKMO-HadGEM1 model overestimates $S W \downarrow_{\text {surf }}$ with respect to the UMD/SRB data. The bias between $S W \downarrow_{\text {surf }}$ from AMIP II in relation to UMD/SRB will be explained in the next section in the context of the different connections between SST and SW $\downarrow_{\text {surf }}$.

The panels of Fig. 3 show the correlations between the anomalies of $S W \downarrow_{\text {surf }}$ from models and UMD/SRB. The spatial correlation patterns indicate higher correlation coefficients (in \%) near the central equatorial Pacific. The field significance of correlation maps is given by the percentage of grid points where the correlations have local significance at the $95 \%$ level. The CNRM-CM3 model accounts for $55 \%$ of the grid area with significant correlation, while the CCSM3 and UKMO-HadGEM1 models give significant correlation for $49 \%$ and $48 \%$ of the grid area, respectively. However, the UKMO-HadGEM1 model gives the highest correlation values in the central equatorial Pacific when compared to the other two models.

\section{Assessment of model variability}

In this section, we compare the variability of SW $\downarrow_{\text {surf }}$ from the UMD/SRB and AMIP II models with the SST variability. The association between $S W \downarrow_{\text {surf }}$ in the central Pacific and SST in the eastern Pacific was previously reported on by Liu and Gautier (1990), Liu et al. (1994), Waliser et al. (1994).
Our objective is to identify not only the areas where $\mathrm{SW} \downarrow_{\text {surf }}$ and SST are linked but also to learn whether the models agree with the satellite-based findings on such relationships. We applied CCA to the three principal component subsets of each field, namely, SW $\downarrow_{\text {surf }}$ and SST. Figures 4 a to e show the spatial configuration of the leading canonical correlation pattern (CCP) for the satellite estimates (UMD/SRB), those corresponding to the models (CCSM3, UKMO-HadGEM1 and CNRN-CM3) and for SST. The SST map corresponds to the CCA between UMD/SRB and SST. In these figures zones are characterized where $S W \downarrow_{\text {surf }}$ and SST are intercorrelated or dynamically linked. The connected regions correspond approximately to the area of El Niño $3.4\left(170^{\circ} \mathrm{W}\right.$ to $120^{\circ} \mathrm{W}, 5^{\circ} \mathrm{S}$ to $5^{\circ} \mathrm{N}$ ) in the case of SST data (Fig. 4e, hereafter SST(3.4)) and to the area of the El Niño $4\left(160^{\circ} \mathrm{E}\right.$ to $150^{\circ} \mathrm{W}, 5^{\circ} \mathrm{S}$ to $5^{\circ} \mathrm{N}$ ) for the $\mathrm{SW} \downarrow_{\text {surf }}$ data (Figs. $4 \mathrm{a}, \mathrm{b}, \mathrm{c}$, $\mathrm{d}$, hereafter $\left.\mathrm{SW} \downarrow_{\text {surf }}(4)\right)$. These figures indicate that a negative (positive) $\mathrm{SW} \downarrow_{\text {surf }}$ over the central Pacific is correlated to warming (cooling) over the eastern Pacific. This mode of SW $\downarrow_{\text {surf }}$ and SST variability represents the ENSO event. Therefore, the atmospheric component of ENSO can be characterized by $S W \downarrow_{\text {surf }}$, in addition to other atmospheric circulation considerations. Figures $4 \mathrm{f}$ to $\mathrm{i}$ show the corresponding Canonical Correlation Coefficients (CCC). The Opposite association can be seen between the time series that represents $S W \downarrow_{\text {surf }}$ variability in relation to the one that represents SST variability. The correlation coefficients between the leading Canonical modes of SST and SW $\downarrow_{\text {surf }}$ are -0.86 , $-0.87,-0.83$ and -0.79 for UMD/SRB, CCSM3, UKMOHadGEM1 and CNRM-CM3, respectively. The signals of 
the 1997/1998 and 1991/1992 ENSOs are stronger in the component of the $S W \downarrow_{\text {surf }}$ (blue line) than in the component of the SST (red line). The CCC contain significant oscillations between the 3.5- and 7-year periods as revealed by power spectra of these time series (not shown). The correlation coefficients did not improve when lagging the time series, probably because the adjustment between $\mathrm{SW} \downarrow_{\text {surf }}$, and SST anomalies is shorter than one month, which is the time interval used in this study.

Figures 5a to e illustrate anomalies or departures from the mean in the Hovmöller representation for SST and SW $\downarrow_{\text {surf }}$ corresponding to UMD/SRB and the three AMIP II models. The shaded contours show the time-longitude evolution for the equatorial Pacific $\left(5^{\circ} \mathrm{S}\right.$ to $\left.5^{\circ} \mathrm{N}\right)$. To the right of each Hovmöller figure, the time series evolution averaged over the above referenced boxes is represented. As expected, the positive (negative) phase of SST in the eastern Pacfic is related to negative (positive) $S W \downarrow_{\text {surf }}$ anomalies in the central Pacific. There is a clear correspondence between amplification and dissipation of the anomalies, which is indicative of a forcing that affects both atmosphere and ocean almost simultaneously. These results agree with Yu and Boer (2002) and Ramanathan and Collins (1991).

The $S W \downarrow_{\text {surf }}$ and SST data over the specific regions previously identified were averaged to determine the connections between SST and SW $\downarrow_{\text {surf. }}$ The correlation and regression coefficients between the anomalies of $S W \downarrow_{\text {surf }}$ and SST time series corresponding to the boxes (designated by UMD/SRB(4), CCSM3(4), UKMO-HadGEM1(4), CNRMCM3(4) and SST(3.4)) are depicted in Table 2. The correlation coefficients measure the significance of the association between the changes in $S W \downarrow_{\text {surf }}$, from simulations and the UMD/SRB model, with SST. The linear regressing between SW $\downarrow_{\text {surf }}$ and SST quantify the response. These results (Table 2) indicate a negative response of $S W \downarrow_{\text {surf }}$ to an increase in SST. The magnitude of SW $\downarrow_{\text {surf }}$ attenuation (in $\mathrm{W} \mathrm{m}^{-2}$ per degree) or "the shading effect" is greater for CNRM-CM3(4) and lower for CCSM3(4), while UMD/SRB(4) and UKMOHadGEM1(4) give a similar response to SST.

The $S W \downarrow_{\text {surf }}$ AMIP II bias relative to the UMD/SRB data is investigated considering the different links between SW $\downarrow_{\text {surf }}$ and SST. For example, UKMO-HadGEM1 offers the best agreement with UMD/SRB based on the correlation coefficient $(0.82)$ and its standard deviation has a value close to the UMD/SRB (Table 3). This model provides a response to SST similar to the one of UMD/SRB (Table 2). The CNRM-CM3 model has the lowest correlation with the $\mathrm{UMD} / \mathrm{SRB}$ (0.74); it has the largest standard deviation and gives a higher response to SST than the response of the UMD/SRB to SST. We can observe in Fig. $2 d$ that this model underestimated $\mathrm{SW} \downarrow_{\text {surf }}$. The correlation coefficient between CCSM3 and UMD/SRB is 0.77 (Table 3), it has a lower standard deviation than UMD/SRB and it shows the lowest response to SST (Table 2), providing negative and positive bias in relation to UMD/SRB (Fig. 2a). Although the analysis of
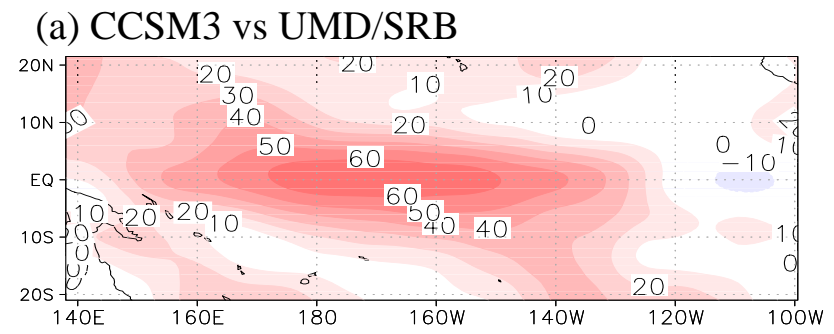

(b) UKMO-HadGEM1 vs UMD/SRB

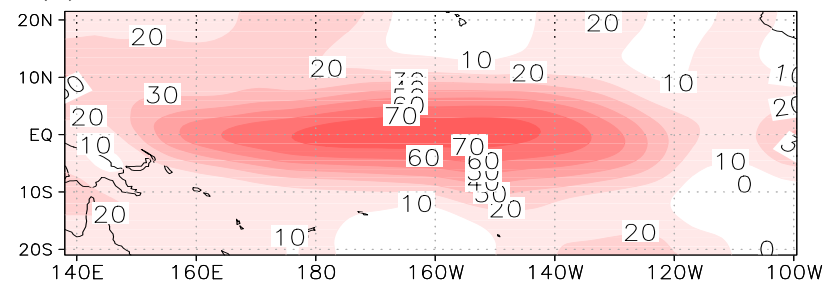

(c) CNRM-CM3 vs UMD/SRB

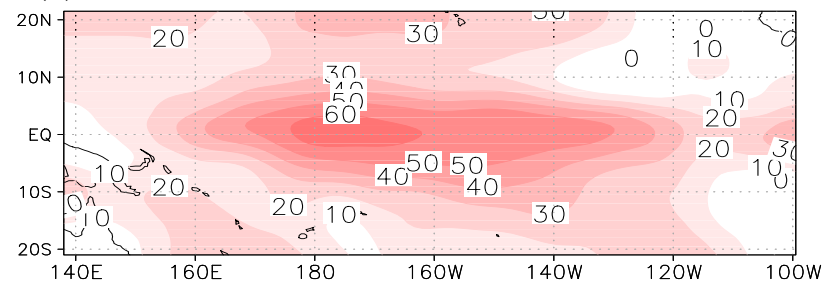

Fig. 3. Correlation patterns between $\mathrm{SW} \downarrow_{\text {surf }}$ from AMIP II models versus UMD/SRB estimates in (\%): (a) CCSM3; (b) UKMOHadGEM1; (c) CNRM-CM3.

the causes of the discrepancies among the models is beyond the scope of this paper, they could be related to different spatial resolutions. For example, the UKMO-HadGEM1 has the finest resolution (Table 1) and the best agreement with UMD/SRB.

The correlated areas of SW $\downarrow$ surf and SST are not colocated because $S W \downarrow_{\text {surf }}$ is strongly impacted by clouds, and thus convection. Convection occurs when the SST exceeds a certain threshold (Graham and Barnett, 1987). As the tropical Pacific is climatologically warmer in the western and colder in the eastern basin, deep convection occurs to the west of the SST anomaly where SST-threshold for deep convection is more easily met. Larson and Hartmann (2003) explained the negative feedback between SST and SW $\downarrow_{\text {surf }}$ in the tropics as result of the increase in the high cloud area from SST warming. Sun et al. (2006) quantified the feedback from the cloud albedo to SST and obtained that many models have a weaker negative feedback than the real atmosphere and the errors may be due to the response of convection.

The changes in SST and SW $\downarrow_{\text {surf }}$ are related to circulation changes affecting cloud distribution. Table 2 gives the correlation and regression coefficients between $\mathrm{SW} \downarrow$ surf 
(a) UMD/SRB

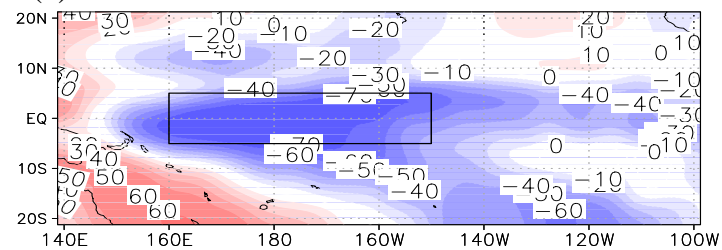

(b) CCSM3

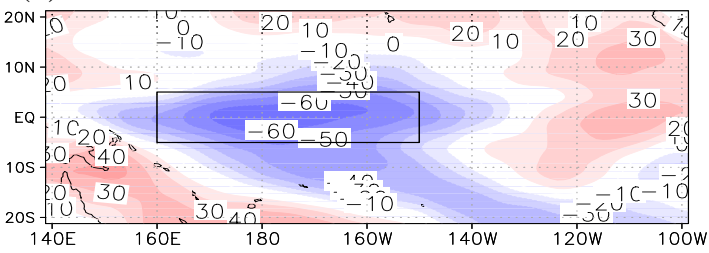

(c) UKMO-HadGEM1

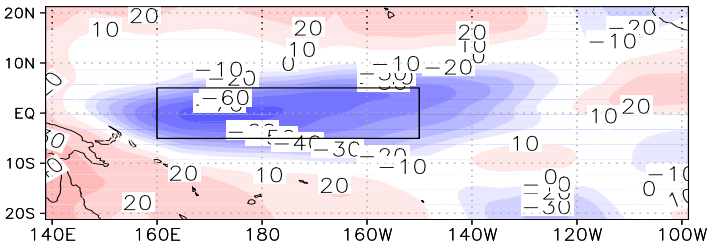

(d) CNRM-CM3

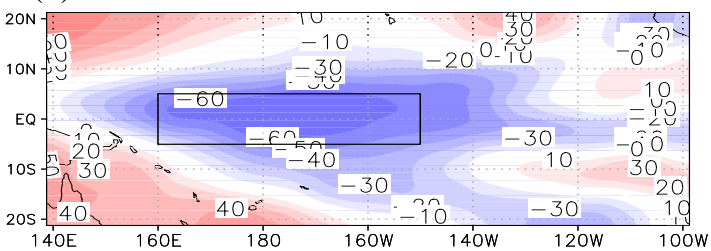

(e) SST

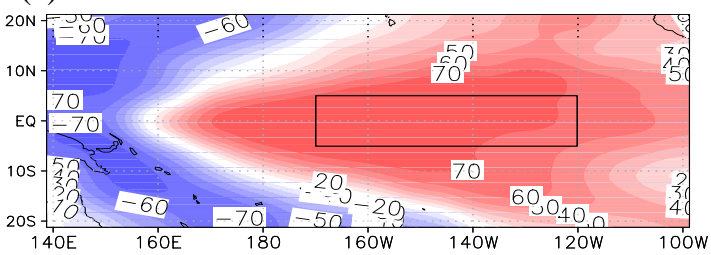

(f) UMD/SRB

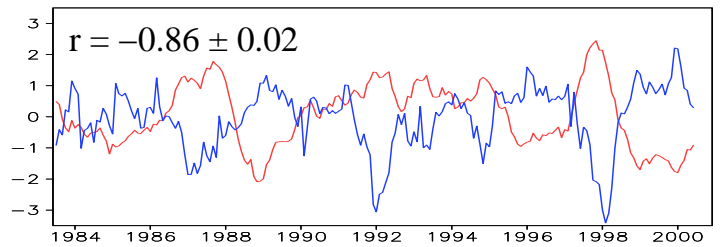

(g) CCSM3

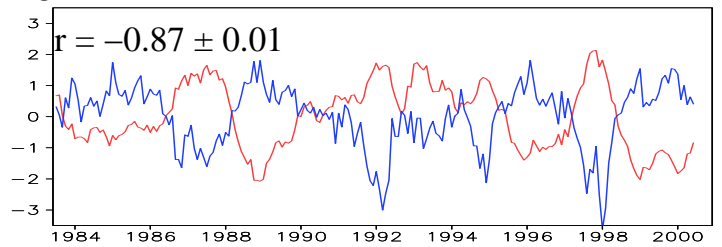

(h) UKMO-HadGEM1

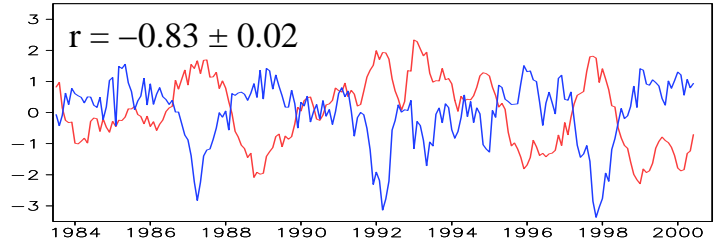

(i) $\mathrm{CNRM}-\mathrm{CM} 3$

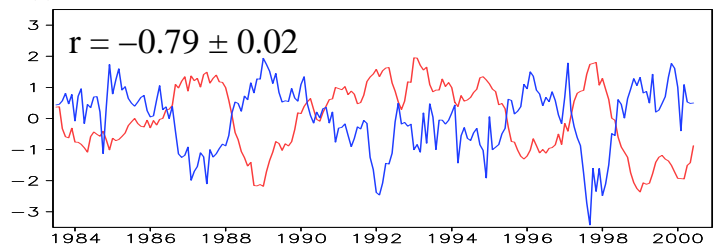

Fig. 4. Canonical correlation patterns in (\%) by regressing the canonical correlation coefficients (CCC) with SW $\downarrow_{\text {surf }}$ data for: (a) UMD/SRB; (b) CCSM3; (c) UKMO-HadGEM1; (d) CNRM-CM3; and (e) SST. The SST pattern corresponds to the analysis between UMD/SRB and SST. The boxes stand out for the connected areas. Canonical correlation coefficients of SW $\downarrow$ surf (blue line) and SST (red line) for: (f) UMD/SRB; (g) CCSM3; (h) UKMO-HadGEM1; (i) CNRM-CM3.

and $\triangle$ SLP. The higher correlation coefficients correspond to the UMD/SRB and UKMO-HadGEM1 results. The responses or regression coefficients of SW $\downarrow_{\text {surf }}$ to $\triangle \mathrm{SLP}$ are positive; these results indicate that $S W \downarrow_{\text {surf }}$ increases with the strengthening of the Walker circulation (Harrison and Larkin, 1998). The regression coefficient is greater in the case of CNRM-CM3 than for the other models.

The analysis of the changes in the tropical Pacific indices, such as $\operatorname{SST}(3.4), \Delta$ SLP and SW $\downarrow_{\text {surf }}(4)$ are of interest because they have effects on many components of the climate system. Figure 6e shows the SST(3.4) time series anomalies with respect to the results of this time series least- square fit to time. The slight tendency of increase is not significant according to Kendall's Z test (0.09). Considering the link between $\mathrm{SW} \downarrow_{\text {surf }}$ and SST over the connected areas, a decrease for the $S W \downarrow_{\text {surf }}$ was expected. However, the UMD/SRB(4) shows a tendency of increase at about $0.52 \mathrm{~W} \mathrm{~m}^{2}$ per year (Table 3 ). This finding is consistent with the study of Pinker et al. (2005), who reported an overall increase in $\mathrm{SW} \downarrow_{\text {surf }}$ at a rate of $0.161 \mathrm{~W} \mathrm{~m}^{-2} \mathrm{yr}^{-1}$ globally averaged and $0.179 \mathrm{~W} \mathrm{~m}^{-2} \mathrm{yr}^{-1}$ over the tropical belt of $20^{\circ} \mathrm{S}$ to $20^{\circ} \mathrm{N}$ for the period 1983 to 2001 . The UMD/SRB(4) increasing trend is significant according to the non-parametric Kendall $\mathrm{Z}$ test $(\mathrm{Z}=2.25)$. For the same period, CCSM3(4), 
(a) SST

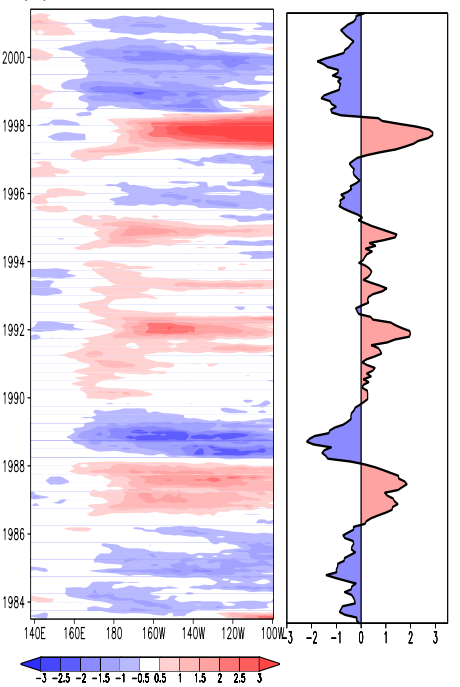

(c) CCSM3

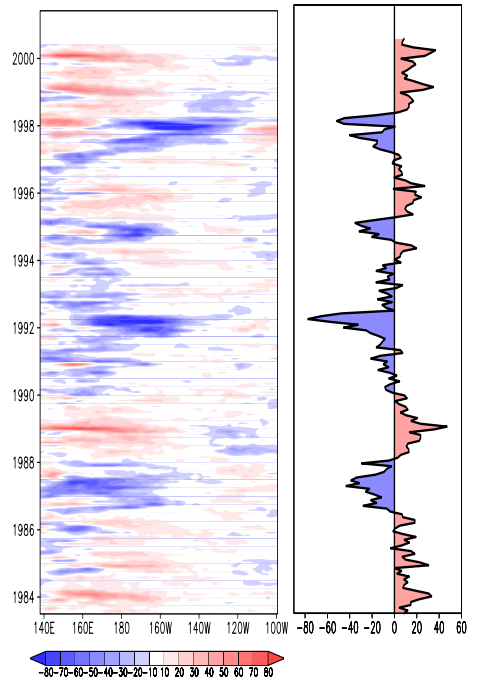

(b) UMD/SRB

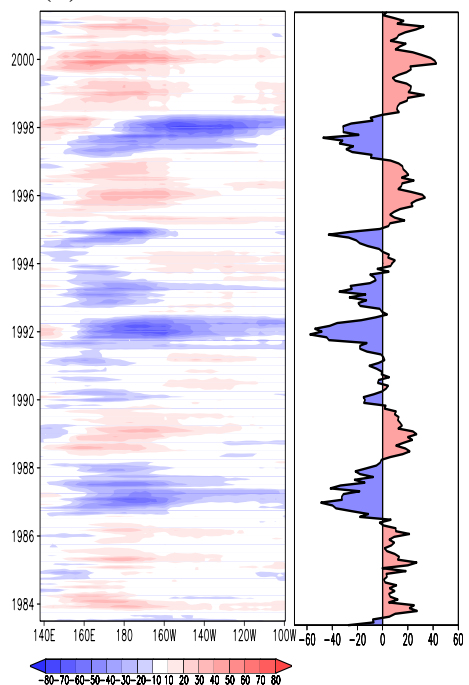

(d) UKMO-HadGEM1

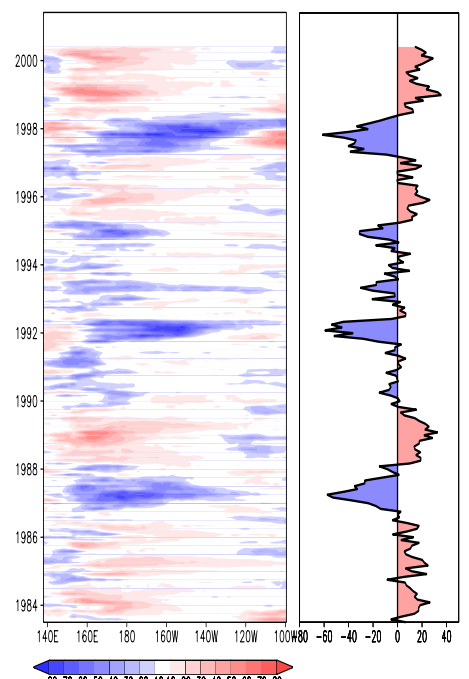

(e) CNRM-CM3

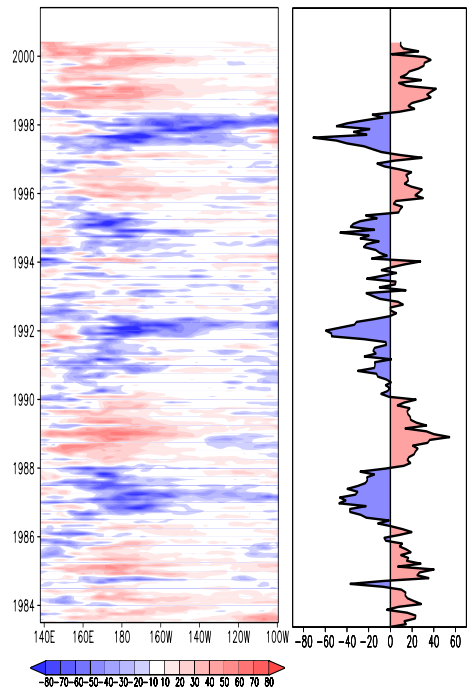

Fig. 5. Time-longitude plot (Hovmöller representation) of the departures of the mean over $5^{\circ} \mathrm{S}$ to $5^{\circ} \mathrm{N}$ for: (a) SST ( ${ }^{\circ} \mathrm{C}$ ), and $\mathrm{SW} \downarrow$ surf for the following (b) UMD/SRB; (c) CCSM3; (d) UKMO-HadGEM1; (e) CNRM-CM3 in $\mathrm{W} \mathrm{m}^{-2}$. The figures to the right of each Hovmöller plot present time series of respective parameters averaged over El Niño 3.4 region for SST and over El Niño 4 region for SW $\downarrow_{\text {surf }}$.

UKMO-HadGEM1(4) and CNRM-CM1(4) do not pass the test for significance in trend. These results are presented in Table 3 and in Figs. 6 a to d, which show the SW $\downarrow_{\text {surf }}$ anomalies and the corresponding time series least-square fit to time. For the period July 1983 to June 2000 the $\triangle$ SLP gives a positive trend of about $3 \mathrm{~Pa}$ per year with a significance of 1.9, according to Kendall's $\mathrm{Z}$ test. This result is in agreement with the positive link between $S W \downarrow$ surf and $\triangle$ SLP.

The association between SW $\downarrow_{\text {surf }}$ and SST is well captured by the AMIP II models, though they do not simulate the increasing trend that is present in the UMD/SRB(4) data. Therefore, it is necessary to investigate longer time series to shed light on the models' deficiencies.

\section{Conclusions}

The ability of models that participated in the AMIP II experiments under the Program for Climate Model Diagnosis and Intercomparison (PCMDI) to simulate downwelling surface shortwave radiation has been examined by comparison with data from UMD/SRB satellites estimates over the equatorial Pacific. The best agreement between the various shortwave fluxes is found to be in the central equatorial $\mathrm{Pa}$ cific, while considerable bias was found over some areas of the tropical Pacific. The various radiative fluxes were analyzed in conjunction with the sea surface temperatures by means of Canonical Correlation Analysis to learn about their 


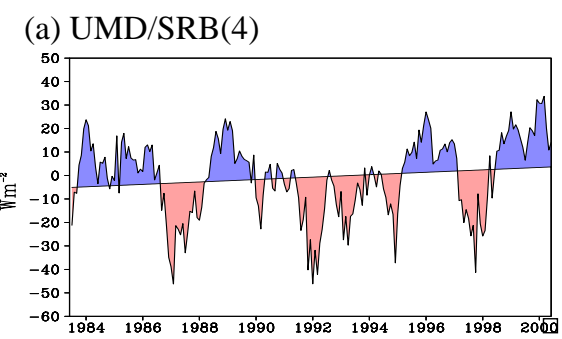

(c) UKMO-HadGEM1(4)

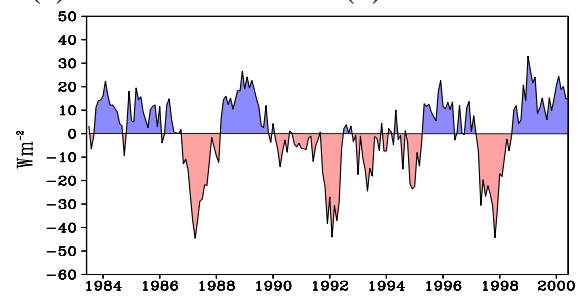

(e) $\operatorname{SST}(3.4)$

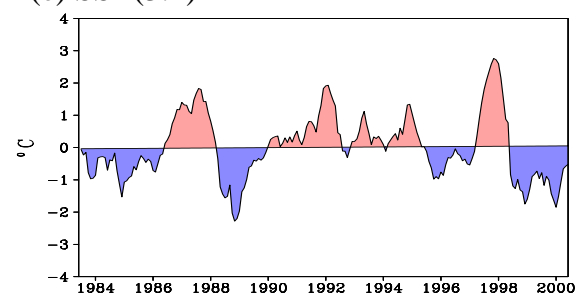

(b) $\operatorname{CCSM} 3(4)$

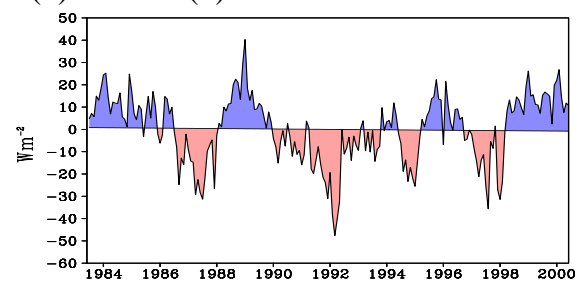

(d) CNRM-CM3(4)

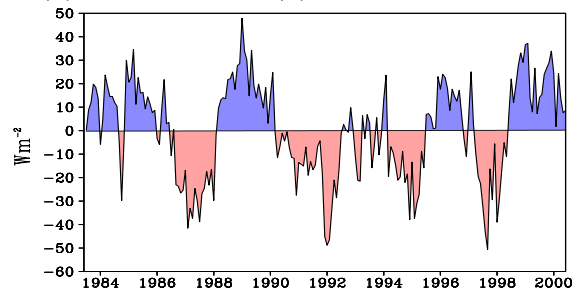

(f) $\triangle$ SLP

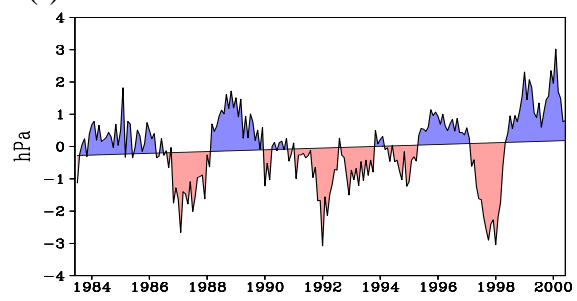

Fig. 6. Time series of $S W \downarrow_{\text {surf }}$ anomalies corresponding to El Niño 4 region for: (a) UMD/SRB; (b) CCSM3; (c) UKMO-HadGEM1; (d) CNRM-CM3 in $\mathrm{W} \mathrm{m}^{-2}$; (e) time series of SST anomalies corresponding to El Niño 3.4 region in ${ }^{\circ} \mathrm{C}$; (f) time series of $\Delta \mathrm{SLP}$ or the difference in sea level pressure over $\left(160^{\circ} \mathrm{W}\right.$ to $80^{\circ} \mathrm{W}, 5^{\circ} \mathrm{S}$ to $\left.5^{\circ} \mathrm{N}\right)$ and over $\left(80^{\circ} \mathrm{E}\right.$ to $160^{\circ} \mathrm{E}, 5^{\circ} \mathrm{S}$ to $\left.5^{\circ} \mathrm{N}\right)$. The straight lines represents the trend of the anomalies.

association and representation of the El Niño-like variability. The $S W \downarrow_{\text {surf }}$ of AMIP II models captured the interannual El Niño variation seen in the $S W \downarrow_{\text {surf }}$ from the UMD/SRB model. The different connections between SW $\downarrow_{\text {surf }}$ and SST can possibly explain the bias of the AMIP II outputs with respect to the UMD/SRB data.

The positive trend found in the $\mathrm{SW} \downarrow_{\text {surf }}$ from the UMD/SRB satellite estimates is not captured by the AMIP II models. The discrepancies between GCM's model data with respect to satellite estimates could be due to uncertainties in the solar absorption by the atmospheric constituents, which needs to be analyzed in depth in order to derive the best projections about the impacts of climate change. The findings of this study will be revisited with updated satellite retrieval techniques and new WCRP CMIP3 multi-model data set to clarify the interrelationships between $\mathrm{SW} \downarrow_{\text {surf }}$ and SST at longer time scales.

Acknowledgements. This work was supported by projects CGL2005-06600-CO3-01/CLI (Spanish Ministry of Science and Technology). Development of schemes for inferring satellite based radiative fluxes was supported under grants NAG11832, NAG59634 and NNG04GD65G from NASA. S. Nigam wishes to acknowledge support of Grants NOAA/CPPA NA17EC1483, and NSF ATM-0649666. We acknowledge NCEP for providing the SST iand SLP data, the international modeling groups for providing their data, the Program for Climate Model Diagnosis and Intercomparison (PCMDI) for collecting and archiving the model data. We acknowledge the developers of GrADS software. We are grateful to three anonymous reviewers for helpful comments.

Topical Editor F. D'Andrea thanks three anonymous referees for their help in evaluating this paper.

\section{References}

Allan, R. P., Ringer, M. A., Pamment, J. A., and Slingo, A.: Simulation of the Earth's radiation budget by the European centre for Medium-Range Weather Forecasts 40-year reanalysis (ERA40), J. Geophys. Res.-Atmos., 109, D18107, doi:10.1029/2004JD004816, 2004.

Bretherton, C. S., Smith, C., and Wallace, J. M.: An intercomparison of methods for finding coupled patterns in climate data, J. Climate, 5, 541-560, 1992.

Chen, J. Y., Carlson, B. E., and Del Genio, A. D.: Evidence for strengthening of the tropical general circulation in the 1990s, Science, 295, 838-841, 2002.

Chou, S. H., Chou, M. D., Chan, P. K., Lin, P. H., and Wang, K. H.: Tropical warm pool surface heat budgets and temperature: Con- 
trasts between 1997/98 El Nino and 1998/99 La Nina, J. Climate, 17, 1845-1858, 2004.

Collins, W. D., Bitz, C. M., Blackmon, M. L., Bonan, G. B., Bretherton, C. S., Carton, J. A., Chang, P., Doney, S. C., Hack, J. J., Henderson, T. B., Kiehl, J. T., Large, W. G., McKenna, D. S., Santer, B. D., and Smith, R. D.: The Community Climate System Model version 3 (CCSM3), J. Climate, 19, 2122-2143, 2006.

Deque, M., Dreveton, C., Braun, A., and Cariolle, D.: The Arpege/ifs atmosphere model - a contribution to the French Community Climate Modeling, Clim. Dynam., 10, 249-266, 1994.

Gordon, C., Cooper, C., Senior, C. A., Banks, H., Gregory, J. M., Johns, T. C., Mitchell, J. F. B., and Wood, R. A.: The simulation of SST, sea ice extents and ocean heat transports in a version of the Hadley Centre coupled model without flux adjustments, Clim. Dynam., 16, 147-168, 2000.

Graham, N. E. and Barnett, T. P.: Sea-Surface Temperature, Surface Wind Divergence, and Convection over Tropical Oceans, Science, 238, 657-659, 1987.

Gupta, S. K., Ritchey, N. A., Wilber, A. C., Whitlock, C. H., Gibson, G. G., and Stackhouse, P. W.: A climatology of surface radiation budget derived from satellite data, part 2, J. Climate, 12, 2691-2710, 1999.

Halthore, R. N., Crisp, D., Schwartz, S. E., Anderson, G. P., Berk, A., Bonnel, B., Boucher, O., Chang, F. L., Chou, M. D., Clothiaux, E. E., Dubuisson, P., Fomin, B., Fouquart, Y., Freidenreich, S., Gautier, C., Kato, S., Laszlo, I., Li, Z., Mather, J. H., Plana-Fattori, A., Ramaswamy, V., Ricchiazzi, P., Shiren, Y., Trishchenko, A., and Wiscombe, W.: Intercomparison of shortwave radiative transfer codes and measurements, Journal of Geophysical Research-Atmospheres, 110, D11206, doi:10.1029/2004JD005293, 2005.

Harrison, D. E. and Larkin, N. K.: El Nino-Southern Oscillation sea surface temperature and wind anomalies, 1946-1993, Rev. Geophys., 36, 353-399, 1998.

IMSL: Fortran subroutines for statistical applications, Stat/libra ry Vols. 1 and 2, Visual Numeric, Inc., 1997.

Jolliffe, I.: Principal Component Analysis, Springer, 2002.

Joseph, R. and Nigam, S.: ENSO evolution and teleconnections in IPCC's twentieth-century climate simulations: Realistic representation?, J. Climate, 19, 4360-4377, 2006.

Kalnay, E., Kanamitsu, M., Kistler, R., Collins, W., Deaven, D., Gandin, L., Iredell, M., Saha, S., White, G., Woollen, J., Zhu, Y., Chelliah, M., Ebisuzaki, W., Higgins, W., Janowiak, J., Mo, K. C., Ropelewski, C., Wang, J., Leetmaa, A., Reynolds, R., Jenne, R., and Joseph, D.: The NCEP/NCAR 40-year reanalysis project, B. Am. Meteorol. Soc., 77, 437-471, 1996.

Larson, K. and Hartmann, D. L.: Interactions among cloud, water vapor, radiation, and large-scale circulation in the tropical climate. Part I: Sensitivity to uniform sea surface temperature changes, J. Climate, 16, 1425-1440, 2003.

Laszlo, I. and Pinker, R. T.: Shortwave cloud-radiative forcing at the top of the atmosphere at the surface and of the atmospheric column as determined from ISCCP C1 data, J. Geophys. Res.Atmos., 98, 2703-2713, 1993.

Li, Z. Q., Whitlock, C. H., and Charlock, T. P.: Assessment of the global monthly mean surface Insolation estimated from satellite measurements using Global Energy-Balance archive data, J. Cli- mate, 8, 315-328, 1995.

Liu, W. and Gautier, C.: Thermal forcing on the tropical Pacific from satellite data, J. Geophys. Res., 95, C8, 13 209-13217, 1990.

Liu, W. T., Zhang, A. Z., and Bishop, J. K. B.: Evaporation and Solar Irradiance as regulators of Sea-Surface Temperature in annual and interannual changes, J. Geophys. Res.-Oceans, 99, 12623 $12637,1994$.

Livezey, R. E. and Smith, T. M.: Considerations for use of the Barnett and Preisendorfer (1987) algorithm for canonical correlation analysis of climate variations, J. Climate, 12, 303-305, 1999.

Martin, D. W., Collimore, C. C., and Hitchman, M. H.: El Nino and La Nina in highly reflective cloud, J. Climate, 17, 3470-3475, 2004.

Pinker, R., Laszlo, I., Whitlock, C., and Charlock, T.: Radiative flux opens new window on climate research, EOS Transactions American Geophysical Union, 76, 145-145, 1995.

Pinker, R. T. and Laszlo, I.: Modeling Surface Solar Irradiance for satellite applications on a global scale, J. Appl. Meteorol., 31, 194-211, 1992.

Pinker, R. T., Zhang, B., and Dutton, E. G.: Do satellites detect trends in surface solar radiation?, Science, 308, 850-854, 2005.

Press, W., Teukolsky, S., Vetterling, W., and Flanery, B.: Numerical Recipes in Fortran 77: The Art of Scientific Computing, Cambridge University Press, 1996.

Ramanathan, V. and Collins, W.: Thermodynamic regulation of ocean warming by cirrus clouds deduced from observations of the 1987 el-niño, Nature, 351, 27-32, 1991.

Reynolds, R. W., Rayner, N. A., Smith, T. M., Stokes, D. C., and Wang, W. Q.: An improved in situ and satellite SST analysis for climate, J. Climate, 15, 1609-1625, 2002.

Smith, T. M. and Reynolds, R. W.: Improved extended reconstruction of SST (1854-1997), J. Climate, 17, 2466-2477, 2004.

Stott, P. A., Jones, G. S., and Mitchell, J. F. B.: Do models underestimate the solar contribution to recent climate change?, J. Climate, 16, 4079-4093, 2003.

Sun, D. Z., Zhang, T., Covey, C., Klein, S. A., Collins, W. D., Hack, J. J., Kiehl, J. T., Meehl, G. A., Held, I. M., and Suarez, M.: Radiative and dynamical feedbacks over the equatorial cold tongue: Results from nine atmospheric GCMs, J. Climate, 19, 4059-4074, 2006.

van Oldenborgh, G., Philip, S., and Collins, M.: El Niño in a changing climate: a multi-model study, Ocean Sci., 1, 81-95, 2005, http://www.ocean-sci.net/1/81/2005/.

Vecchi, G. A. and Harrison, D. E.: On the termination of the 2002-03 El Nino event, Geophys. Res. Lett., 30(18), 1964, doi:10.1029/2003GL017564, 2003.

Vecchi, G. A., Soden, B. J., Wittenberg, A. T., Held, I. M., Leetmaa, A., and Harrison, M. J.: Weakening of tropical Pacific atmospheric circulation due to anthropogenic forcing, Nature, 441(30), 73-76, 2006.

von Storch, H. and Zwiers, F.: Statistical analysis in climate research, Cambridge University press, 1999.

Waliser, D. E., Blanke, B., Neelin, J. D., and Gautier, C.: Shortwave feedbacks and el-Niño-Southern-Oscillation - forced ocean and coupled ocean-atmosphere experiments, J. Geophys. Res.Oceans, 99, 25 109-25 125, 1994.

Wang, X. L. L., Wen, Q. H., and Wu, Y. H.: Penalized maximal $\mathrm{t}$ test for detecting undocumented mean cha nge in climate data 
series, J. Appl. Meteorol. Climatol., 46, 916-931, 2007.

Weare, B. C. and Mokhov, I. I.: Evaluation of total cloudiness and its variability in the atmospheric model intercomparison project, J. Climate, 8, 2224-2238, 1995.

Weatherhead, E. C., Reinsel, G. C., Tiao, G. C., Meng, X. L., Ch oi, D. S., Cheang, W. K., Keller, T., DeLuisi, J., Wuebbles, D. J., Kerr, J. B., Miller, A. J., Oltmans, S. J., and Frederick, J. E.: Factors affecting the detection of trends: Statistical considerations and app lications to environmental data, J. Geophys. Res.Atmos., 103, 17 149-17 161, 13, 1998.

Whitlock, C. H., Charlock, T. P., Staylor, W. F., Pinker, R. T., Laszlo, I., Ohmura, A., Gilgen, H., Konzelman, T., Dipasquale, R. C., Moats, C. D., Lecroy, S. R., and Ritchey, N. A.: First global WCRP shortwave surface radiation budget dataset, B. Am. Meteorol. Soc., 76, 905-922, 1995.

Wielicki, B. A., Wong, T. M., Allan, R. P., Slingo, A., Kiehl, J. T., Soden, B. J., Gordon, C. T., Miller, A. J., Yang, S. K., Randall, D. A., Robertson, F., Susskind, J., and Jacobowitz, H.: Evidence for large decadal variability in the tropical mean radiative energy budget, Science, 295, 841-844, 2002.
Wilks, D.: Statistical methods in the atmospheric sciences, Academic Press, 2 edn., 2006.

Wilks, D. S.: Resampling hypothesis tests for autocorrelated fields, J. Climate, 10, 65-82, 1997.

Wiscombe, W. J.: Delta-M method - rapid yet accurate radiative flux calculations for strongly asymmetric phase functions, J. Atmos. Sci., 34, 1408-1422, 1977.

Xia, X. A., Wang, P. C., Chen, H. B., and Liang, F.: Analysis of downwelling surface solar radiation in China from National Centers for Environmental Prediction reanalysis, satellite estimates, and surface observations, J. Geophys. Res.-Atmos., 111, D09103, doi:10.1029/2005JD006405, 2006.

$\mathrm{Yu}, \mathrm{B}$. and Boer, G. J.: The roles of radiation and dynamical processes in the El Nino-like response to global warming, Clim. Dynam., 19, 539-553, 2002.

Zhang, B. L., Pinker, R. T., and Stackhouse, P. W.: An empirical orthogonal function iteration approach for obtaining homogeneous radiative fluxes from satellite observations, J. Appl. Meteorol. Climatol., 46, 435-444, 2007. 